УДК: 616.31-085

DOI 10.18413/2687-0940-2020-43-2-274-284

\title{
ПРИМЕНЕНИЕ КОМБИНИРОВАННОЙ ТЕРАПИИ КВЧ И ИММУНОМОДУЛЯТОРА ДЛЯ КОРРЕКЦИИ ЦИТОКИНОВ ПРИ ХРОНИЧЕСКОМ ГЕНЕРАЛИЗОВАННОМ ПАРОДОНТИТЕ
}

\section{APPLICATION OF COMBINATION THERAPY OF KVF AND IMMUNOMODULATOR FOR CYTOKINE CORRECTION IN CHRONIC GENERALIZED PERIODONTITIS}

\author{
В.В. Масляков ${ }^{1}$, А.А. Цымбал ${ }^{2}$, Е.А. Пронина ${ }^{1}$, А.Г. Прошин ${ }^{1}$, А.В. Ильюхин ${ }^{1}$ \\ V.V. Maslyakov ${ }^{1}$, A.A. Tsymbal ${ }^{2}$, E.A. Pronina ${ }^{1}$, A.G. Proshin ${ }^{1}$, A.V. Ilyukhin ${ }^{1}$ \\ ${ }^{1}$ Частное учреждение образовательная организация высшего образования «Саратовский \\ медицинский университет «Реавиз», \\ Россия, 410012, г. Саратов, ул. Верхний рынок, корпус 10 \\ 2 Московский государственный медицинский университет имени И.М. Сеченова, \\ Россия, 119991, Москва, ул. Трубецкая, д. 8, стр. 2 \\ ${ }^{1}$ Private institution educational organization of higher education \\ «Saratov Medical University «Reaviz», \\ 10 Verhnij rynok St., Samara, 410012, Russia \\ ${ }^{2}$ Moscow State Medical University named after I.M. Sechenov, \\ 8 house, 2 building Trubetskaya St., Moscow, 119991, Russia \\ E-mail: maslyakov@inbox.ru
}

\begin{abstract}
Аннотация
Цель работы - улучшить результаты лечения хронического генерализованного пародонтита путем восстановления цитокинов с использованием КВЧ-терапии и иммуномодулятора. Для проведения исследования было привлечено 240 человек. Программа исследования состояла из включения нескольких групп пациентов. Первую группу составили 80 пациентов с установленным диагнозом ХГП, получавших традиционное лечение. Во вторую группу были включены 80 пациентов, которым обычная терапия была дополнена применением КВЧ-терапии, третья группа состояла из 80 человек, лечение которых помимо обычной терапии было дополнено введением иммуномодулятора полиоксидония, который применялся per os, по 1 таблетке 2 раза в день $3 a 30$ мин. до еды в течение 10 дней, одновременно с этим проводился сеанс КВЧ-терапии. Пациентам двум других клинических групп в качестве патогенетической терапии, которая была направлена на улучшение иммунного статуса и скорейшее купирование признаков воспаления в ткани пародонта, была использована КВЧ-терапия. В результате проведенного исследования было установлено, что раздельное применение КВЧ-терапии и иммуномодуляторов при лечении хронического генерализованного пародонтита легкой и средней степени не приводит к более быстрому восстановлению показателей интерлекинов в сыворотке крови. Для более быстрого восстановления интерлекинов в сыворотке крови необходимо одновременное применение КВЧ-терапии и иммуномодулятора. В качестве иммуномодулятора рекомендуем использовать полиоксидоний в таблетированной форме, за 20-30 минут до приема пищи, каждый день 2 раза в сутки, семь дней.
\end{abstract}

\footnotetext{
Abstract

The aim of the work is to improve the results of treatment of chronic generalized periodontitis by recovery of cytokines with the use of VHF therapy and immunomodulator. 240 people were recruited to conduct the study. The study program consisted of including several groups of patients. The first group consisted of 80 patients diagnosed with $\mathrm{HCP}$ who received traditional treatment. In the second group 80 patients were included, to whom the usual therapy was supplemented by the use of VHF therapy, the third group consisted of 80 people, the treatment of which in addition to the usual therapy was supplemented by the introduction
} 
of an immunomodulator - polyoxidonium, which was used per os, 1 tablet 2 times a day 30 minutes before meals for 10 days, at the same time a session of BHF therapy was carried out. The patients of the other two clinical groups, as pathogenetic therapy, which was aimed at improving immune status and early reduction of signs of inflammation in periodontal tissue, were used KVF therapy. As a result of the study, it was found that the separate use of VHF therapy and immunomodulators in the treatment of chronic generalized light and moderate periodontitis does not lead to a faster recovery of blood serum interlexins. For faster reduction of interlexins in blood serum it is necessary to simultaneously use VHF therapy and immunomodulator. As immunomodulator it is recommended to use polyoxidonium in tablet form, 20-30 minutes before meals, every day 2 times a day, seven days.

Ключевые слова: хронический генерализованный пародонтит, иммуномодулятор, цитокины. Keywords: chronic generalized periodontitis, immunomodulator, cytokines.

\section{Введение}

К одному из факторов, способствующему развитию хронического генерализованного пародонтита (ХГП), относят изменения в иммунном статусе организма [Попова и др., 2010; Масляков и др., 2019]. Установлено, что это заболевание приводит к изменениям цитокинов как в слюнной жидкости, так и в сыворотки крови у таких пациентов [Ошноков и др., 2015; Прошин и др., 2018]. Все это потребовало поисков и внедрения методик, направленных на коррекцию этих нарушений при ХГП. Одной из таких методик является применение крайне высоких частот (КВЧ) [Казанцев и др., 2015], а также иммуномодуляторов, в частности полиоксидония [Блашкова и др., 2010] для лечения этой патологии. Однако, несмотря на большое количество публикаций, посвященных этому вопросу, проблема далека от окончательного разрешения.

Цель исследования - улучшить результаты лечения хронического генерализованного пародонтита путем восстановления цитокинов с использованием КВЧ-терапии и иммуномодулятора.

\section{Материалы и методы обследования}

Для проведения исследования было привлечено 240 человек. Базой для проведения исследования послужила ГАУЗ Энгельсская городская стоматологическая поликлиника № 1 в период с 2000 года по 2019 год.

Программа исследования состояла из включения нескольких групп пациентов. Первую группу составили 80 пациентов с установленным диагнозом ХГП, получавших традиционное лечение. Во вторую группу были включены 80 пациентов, которым обычная терапия была дополнена применением КВЧ-терапии, третья группа состояла из 80 человек, лечение которых помимо обычной терапии было дополнено введением иммуномодулятора - полиоксидония, который применялся per os, по 1 таблетке 2 раза в день за 30 мин. до еды в течение 10 дней, одновременно с этим проводился сеанс КВЧ-терапии [Булкина и др., 2018]. Пациентам двум других клинических групп в качестве патогенетической терапии, которая была направлена на улучшение иммунного статуса и скорейшее купирование признаков воспаления в ткани пародонта, была использована КВЧ-терапия. Для этого использовался аппарат, вырабатывающий КВЧ-волны «Явь-1». Данный аппарат имел следующие технические характеристики: длина волны находилась в пределах 5,5 мм, отклонение составляло в пределах не больше \pm 150 МГц. Мощность на выходе находилась в пределах от 22 до 25 мВт. Плотность мощности на выходе из рупора около $10 \mathrm{мBт} / \mathrm{cm}^{2}$. Время продолжительности одного сеанса, которое затрачивалось на каждого пациента, составляло около 30 мин. Общее количество процедур составило 10 штук, процедуры проводились один раз в день, ежедневно. Противопоказаниями для выполнения данной процедуры служили общемедицинские противопоказания и/или индивидуальная непереносимость процедуры, а также отказ пациента от проведения физиопроцедуры. Для 
проведения КВЧ-терапии была применена методика, которая была ранее разработана и внедрена в практику [Истомина, 2012]. При этом оказывалось воздействие на биологически активные точки, расположенные в области лицевого черепа. Возраст обследованных колебался в пределах от 18 лет до 47 лет. В исследования включались пациенты, имеющие установленный диагноз хронического генерализованного пародонтита легкой и средней степени тяжести, которые дали свое письменное согласие на участие в исследовании. Не были включены пациенты, отказавшиеся от участия в исследовании, пациенты, у которых в процессе проведения лечебных процедур развились осложнения, потребовавшие отмены введения лекарственных препаратов или физиопроцедуры. Всем, кто принимал участие в исследовании, были разъяснены цели и задачи, после этого они давали согласие на участие в проведении исследования. План исследования был заслушан и одобрен локальным этическим комитетом медицинского университета «Реавиз».

При наличии патологии пародонта в случае обращения за медицинской помощью проводилось исследование состояния ротовой полости, которое проводили комплексно [Соболева и др., 2017]. Данные, полученные в ходе сбора анамнестических и клинических данных, заносили в историю болезни, утверждённую по форме № 043/у. Диагноз заболеваний пародонтальной ткани формулировали с учетом рекомендаций, которые были приняты на XVI Пленуме Всесоюзного общества стоматологов в 1983 году с дополнениями в 2001 году Президиумом секции пародонтологии Российской академии стоматологии, которые вынесли рекомендации формулировке диагнозов заболеваний пародонтальной ткани. Стоматологический статус оценивался согласно рекомендациям, предложенным В.С. Ивановым [Иванов, 2001]. Клинический осмотр включал в себя оценку состояния прикуса, определяли зубную формулу, наличие тяжистых элементов, состояние уздечек, твердой зубной ткани, наличие травматической артикуляции, наличие или отсутствие экссудативного выпота, а при наличии такового - его характер. Состояние слизистых оболочек, их цветовую гамму: наличие гипертермической реакции или цианоза [Булкина и др., 2011]. Была ли гипертрофия края десны, кровоточивость десны, присутствие мягкого налета на зубах, наличие зубных отложений, которые располагались над деснами или под ними. Помимо этого, определялась глубина пародонтального кармана [Крайнов и др., 2017], степень зубной подвижности [Морозов и др., 2016]. Рассчитывался пародонтальный индекс. Оценку выраженности изменений, связанных с воспалением, осуществляли с помощью величины папиллярно-маргинально-альвеолярного индекса [Караков и др., 2017].

Проведено изучение общего количества комплемента, его С3- и С4-компонентов, содержание интерлекинов (IL), которые отнесены к провоспалительным: IL-1 $\beta$, IL-2, IL-6, IL-8, а также противоспалительных IL: IL-4, IL-10. Помимо этого, в плазме крови определяли количество фактора некроза опухоли (TNF $\alpha)$ и интерферона- $\gamma(\mathrm{IFN}-\gamma)$ в плазме крови. Исследования проводились с использованием наборов реагентов ProCon, произведенных в г. Санкт-Петербурге. Для определения этих параметров использовался метод МФА [Караулов, 1999].

Результаты, полученные в ходе исследования, подвергали статистической обработке. Для этого использовали пакетное программное обеспечение Statistica 6.0. С помощью критерия Шапиро - Уилка осуществлялась проверки гипотезы о видовом распределении. Исходя из того факта, что большинство данных, которые были получены в результате исследования, не соответствовали закону нормального распределения, был выбран Uкритерий Манна - Уитни, используемый для сравнения полученных данных. После получения данного критерия производился расчет Z-критерия, а также показателя достоверности, который обозначали буквой р. К статистически значимым относили те различия, которые соответствовали $\mathrm{p}<0,05$. Помимо этого, производился расчет коэффициента ранговой корреляции Спирмена (R), а также его достоверность - 


\section{Результаты и их обсуждение}

При исследовании показателей, характеризующих систему комплемента у пациентов с установленным диагнозом ХГП легкой степени, установлено, что в основной группе происходило статистически достоверное снижение общего количества комплемента в плазме крови, который составил $116 \pm 0,5 \mathrm{ME/мл,} \mathrm{тогда} \mathrm{как} \mathrm{в} \mathrm{группе} \mathrm{сравнения}-224 \pm 0,7 \mathrm{ME} / \mathrm{MЛ}$ ( $<<0,05)$. Помимо общего количества комплемента в основной группе было выявлено статистически достоверное снижение С3-фракции комплемента до 9,4 г/л, в группе сравнения этот показатель составил $12,7 \pm 0,5$ г/л $(\mathrm{p}<0,05)$, а также C4-фракции комплемента, который составил соответственно $0,09 \pm 0,5$ г/л и $0,19 \pm 0,4$ г/л $(\mathrm{p}<0,05)$. Результаты, полученные при исследовании содержания интерлекинов, представлены в таблице 1.

Таблица 1

Table 1

Показатели содержания интерлекинов у пациентов с ХГП легкой степени и группы сравнения $(\mathrm{M} \pm \mathrm{m})$

Interlequin levels in patients with mild chronic generalized periodontitis and

comparison group $(\mathrm{M} \pm \mathrm{m})$

\begin{tabular}{|c|c|c|}
\hline \multirow{2}{*}{$\begin{array}{c}\text { Исследуемые показатели, } \\
\text { пг/мл }\end{array}$} & \multicolumn{2}{|c|}{ Полученные результаты в группах } \\
\cline { 2 - 3 } & основная $(\mathrm{n}=120)$ & сравнения $(\mathrm{n}=20)$ \\
\hline TNF $\alpha$ & $7,31 \pm 0,3^{*}$ & $3,75 \pm 0,7$ \\
\hline IL-1 $\beta$ & $8,43 \pm 0,4^{*}$ & $5,92 \pm 0,5$ \\
\hline IL-6 & $4,36 \pm 0,5^{*}$ & $1,44 \pm 0,4$ \\
\hline IL-8 & $33,4 \pm 0,7^{*}$ & $24,8 \pm 0,8$ \\
\hline IL-2 & $0,09 \pm 0,8$ & $0,07 \pm 0,9$ \\
\hline IL-4 & $0,87 \pm 0,7$ & $0,85 \pm 0,8$ \\
\hline IL-10 & $29,6 \pm 0,9^{*}$ & $32,6 \pm 0,7$ \\
\hline IFN- $\gamma$ & $2,04 \pm 0,7^{*}$ & $4,07 \pm 0,6$ \\
\hline
\end{tabular}

Примечание: здесь и далее * - знак статистической достоверности.

Как видно из данных, представленных в таблице 1, у пациентов с ХГП легкой степени были отмечены изменения большинства интерлекинов, за исключением IL-2 и IL-4. При этом происходило статистически достоверное увеличение провоспалительных интерлекинов и снижение противовоспалительных.

На основании проведенных исследований можно сделать следующее заключение. У пациентов, страдающих ХГП легкой степени, выявлены изменения как в клеточном звене иммунной системы, так и в гуморальном звене системы иммунитета. Значительное место в патогене развития ХГП легкой степени принадлежит медиаторам, которые вызывают деструкцию ткани, вследствие этого происходит развитие местных воспалительных реакций. Это подтверждается тем, что у пациентов с этой патологией выявлены статически достоверные изменения практически всех интерлекинов в сыворотке крови. При этом происходило увеличение интерлекинов, относящихся к провопалительным и снижение интерлекинов, которые относятся к противовоспалительным.

При исследовании аналогичных показателей у пациентов с ХГП средней степени полученные изменения были аналогичны изменениям, которые были выявлены у пациентов с ХГП легкой степени. При этом считаем необходимым отметить тот факт, что изменения в группе пациентов с ХГП средней степени были более выражены.

При исследовании показателей, характеризующих систему комплемента у пациентов с установленным диагнозом ХГП средней степени, установлено, что в данной группе, как и у пациентов с ХГП легкой степени, происходило статистически достоверное увеличение общего количества комплемента в плазме крови до $107 \pm 0,3 \mathrm{ME} /$ мл, С3-фракции комплемента до 7,2 \pm 0,5 г/л, а также C4-фракции комплемента, который составил 
$0,09 \pm 0,5$ г/л и $0,14 \pm 0,7$ г/л $(\mathrm{p}<0,05)$. Результаты, полученные при исследовании содержания интерлекинов, у пациентов с ХГП средней степени представлены в таблице 2.

Таблица 2

Table 2

Показатели содержания интерлекинов у пациентов с ХГП средней степени и группы сравнения $(\mathrm{M} \pm \mathrm{m})$

Interlequin levels in patients with moderate chronic generalized periodontitis and comparison group $(\mathrm{M} \pm \mathrm{m})$

\begin{tabular}{|c|c|c|}
\hline \multirow{2}{*}{$\begin{array}{c}\text { Исследуемые показатели, } \\
\text { пг/мл }\end{array}$} & \multicolumn{2}{|c|}{ Полученные результаты в группах } \\
\cline { 2 - 3 } & основная $(\mathrm{n}=120)$ & сравнения $(\mathrm{n}=20)$ \\
\hline TNF $\alpha$ & $9,21 \pm 0,6^{*}$ & $3,75 \pm 0,7$ \\
\hline IL-1 $\beta$ & $11,23 \pm 0,2^{*}$ & $5,92 \pm 0,5$ \\
\hline IL-6 & $12,37 \pm 0,8^{*}$ & $1,44 \pm 0,4$ \\
\hline IL-8 & $38,7 \pm 0,4^{*}$ & $24,8 \pm 0,8$ \\
\hline IL-2 & $0,04 \pm 0,5$ & $0,07 \pm 0,9$ \\
\hline IL-4 & $0,88 \pm 0,9$ & $0,85 \pm 0,8$ \\
\hline IL-10 & $25,4 \pm 0,9^{*}$ & $32,6 \pm 0,7$ \\
\hline IFN- $\gamma$ & $1,06 \pm 0,3^{*}$ & $4,07 \pm 0,6$ \\
\hline
\end{tabular}

Как свидетельствуют данные, представленные в таблице 2, у пациентов с ХГП средней степени выявлены те же изменения в показателях интерлекинов, как и в группе с ХГП легкого течения. Однако данные изменения были более выражены, чем в первой группе пациентов.

Вторым этапом было проведено лечение ХГП. Для этой цели были сформированы два группы, в которые вошли пациенты с ХГП легкой и средней степени. Для удобства исследования каждая группа была разделена на три подгруппы. В первую вошли 20 пациентов с ХГП, которым лечение проводилось без применения КВЧ-терапии (группа сравнения 1), во вторую - 20 человек, лечение которых было дополнено КВЧ-терапией (основная группа), третья подгруппа включала еще 20 пациентов, которым в комплексную терапию лечения ХГП легкой степени был включен иммуномодулятор (группа сравнения 2). Для контроля была сформирована третья группа, куда вошли 20 добровольцев без установленной патологии, являвшихся относительно здоровыми (группа сравнения 3). Забор биологического материала у обследованных третьей группы осуществлялся однократно, а у пациентов первой и второй группы - в динамике исследования. При исследовании показателей, характеризующих систему комплемента, было выявлено, что в первые сутки после начала лечения во всех группах было отмечено статистически достоверное снижение показателей общего количества комплемента в плазме крови, С3-фракции комплемента, а также C4-фракции комплемента $(\mathrm{p}<0,05)$. При этом в динамике лечения данные показатели существенных изменений не претерпевали и оставались практически без изменений во всех группах, независимо от проводимого лечения. Изменения данных показателей у пациентов этой группы, независимо от проводимого лечения, отмечены к пятнадцатым суткам. На пятнадцатые сутки происходили статистически достоверные изменения в анализируемых показателях, которые стали соответствовать данным, полученным в группе сравнения из обследованных без установленной патологии.

Подобные изменения, которые были выявлены в группе пациентов с ХГП средней степени, были получены при исследовании содержания интерлекинов. В результате исследования содержания интерлекинов у пациентов с ХГП средней степени было установлено, что после первых суток после начала лечения, также как и у пациентов с легкой степенью, выявлены изменения практически всех интерлекинов, за исключением IL-2 и IL-4. При этом происходило статистически достоверное увеличение провоспатительных интерлекинов и снижение противовоспалительных. Происходило статистически достоверное увеличение интерлекинов, которые отнесены к провоспалительным, и снижение противовоспалительных. Данные показатели существенно не изменялись в процессе проводимого 
лечения, независимой терапии. Изменения данных показателей было выявлено к пятнадцатым суткам, когда происходило статистически достоверное восстановление показателей и соответствие их данным, которые являются физиологически нормальными.

Как показывают проведенные исследования, применение КВЧ-терапии и иммуномодулирующей терапии раздельно в комплексном лечении пациентов с ХГП легкой и средней степени не приводит к более быстрому восстановлению иммунологических показателей и купированию воспалительных явлений в ткани пародонта. В связи с этим нами была разработана методика, предусматривающая одновременное применение иммуномодуляторов и КВЧ-терапии у пациентов с ХГП легкой и средней степени. КВЧ-терапия применялась по ранее описанной методике. В состав основных групп вошло по 20 пациентов, страдающих ХГП, легким и среднем течением. В результате проведенных исследований было установлено, что показатели, характеризующие систему комплемента у пациентов с установленным диагнозом ХГП легкой степени, после проведения комплексного и традиционного лечения улучшились. В первые сутки после начала лечения в обеих исследуемых группах было зарегистрировано статистически достоверное снижение общего количества комплемента в плазме крови, который составил $116 \pm 0,5 \mathrm{ME} /$ мл. Помимо общего количества комплемента в основной группе, а также группе сравнения, было выявлено статистически достоверное снижение С3-фракции комплемента до 9,4 г/л и С4-фракции комплемента, который составил $0,09 \pm 0,5$ г/л. В динамике данные показатели изменились следующим образом: в основной группе к третьим суткам было зарегистрировано увеличение общего количества комплемента в плазме крови до $120 \pm 0,6 \mathrm{ME/мл,} \mathrm{его} \mathrm{С3-фракции} \mathrm{-} \mathrm{до} \mathrm{10,2} \pm$ 0,2 г/л и C4-фракции - до 0,10 $\pm 0,7$ г/л. Из представленных данных видно, что в основной группе происходило увеличение исследуемых показателей, однако они не достигали физиологически нормальных величин. Полное восстановление этих показателей было зарегистрировано к седьмым суткам от начала лечения. В группе сравнения существенной динамики в исследуемых показателях до десятых суток отмечено не было, на десятые сутки данные показатели стали соответствовать физиологически нормальным.

Результаты исследования содержания интерлекинов у пациентов с ХГП легкой степени показали, что после первых суток после начала лечения выявлены изменения практически всех интерлекинов, за исключением IL-2 и IL-4, как в основной группе, так и в группе сравнения. При этом происходило статистически достоверное увеличение провоспатительных интерлекинов и снижение противовоспалительных. Происходило статистически достоверное увеличение интерлекинов, которые отнесены к провоспалительным и снижение противовоспалительных. Полученные результаты представлены в таблице 3.

Таблица 3

Table 3

Показатели содержания интерлекинов у пациентов с ХГП легкой степени и группы сравнения, полученные в первые сутки после начала лечения $(\mathrm{M} \pm \mathrm{m})$

Interlequin levels in patients with chronical generalized light-degree periodontitis and comparison groups obtained on the first day after starting treatment $(\mathrm{M} \pm \mathrm{m})$

\begin{tabular}{|c|c|c|}
\hline \multirow{2}{*}{$\begin{array}{c}\text { Исследуемые показатели, } \\
\text { пг/мл }\end{array}$} & \multicolumn{2}{|c|}{ Полученные результаты в группах } \\
\cline { 2 - 3 } & основная $(\mathrm{n}=20)$ & сравнения $(\mathrm{n}=20)$ \\
\hline TNF $\alpha$ & $7,31 \pm 0,3^{*}$ & $6,98 \pm 0,5^{*}$ \\
\hline IL-1 $\beta$ & $8,43 \pm 0,4^{*}$ & $8,23 \pm 0,1^{*}$ \\
\hline IL-6 & $4,36 \pm 0,5^{*}$ & $4,26 \pm 0,6^{*}$ \\
\hline IL-8 & $33,4 \pm 0,7^{*}$ & $32,9 \pm 0,4^{*}$ \\
\hline IL-2 & $0,09 \pm 0,8$ & $0,10 \pm 0,4$ \\
\hline IL-4 & $0,87 \pm 0,7$ & $0,89 \pm 0,5$ \\
\hline IL-10 & $29,6 \pm 0,9^{*}$ & $29,8 \pm 0,3^{*}$ \\
\hline IFN- $\gamma$ & $2,04 \pm 0,7^{*}$ & $2,06 \pm 0,7^{*}$ \\
\hline
\end{tabular}


К третьим суткам от начала лечения в группе сравнения существенных изменений выявлено не было, в основной группе регистрировалось снижение провоспалительных интерлекинов и увеличение противовоспалительных интерлекинов, однако данные показатели не достигали физиологически нормальных величин. Полученные результаты представлены в таблице 4.

Таблица 4

Table 4

Показатели содержания интерлекинов у пациентов с ХГП легкой степени и группы сравнения, полученные на третьи сутки после начала лечения $(\mathrm{M} \pm \mathrm{m})$

Interlequin levels in patients with mild chronic generalized periodontitis and comparison groups obtained on the third day after the start of treatment $(\mathrm{M} \pm \mathrm{m})$

\begin{tabular}{|c|c|c|}
\hline \multirow{2}{*}{$\begin{array}{c}\text { Исследуемые показатели, } \\
\text { пг/мл }\end{array}$} & \multicolumn{2}{|c|}{ Полученные результаты в группах } \\
\cline { 2 - 3 } & основная $(\mathrm{n}=20)$ & сравнения $(\mathrm{n}=20)$ \\
\hline TNF $\alpha$ & $5,11 \pm 0,7^{*}$ & $6,98 \pm 0,5^{*}$ \\
\hline IL-1 $\beta$ & $7,23 \pm 0,6^{*}$ & $8,23 \pm 0,1^{*}$ \\
\hline IL-6 & $3,16 \pm 0,8^{*}$ & $4,26 \pm 0,6^{*}$ \\
\hline IL-8 & $30,1 \pm 0,5^{*}$ & $32,9 \pm 0,4^{*}$ \\
\hline IL-2 & $0,09 \pm 0,8$ & $0,10 \pm 0,4$ \\
\hline IL-4 & $0,87 \pm 0,7$ & $0,89 \pm 0,5$ \\
\hline IL-10 & $30,1 \pm 0,9^{*}$ & $29,8 \pm 0,3^{*}$ \\
\hline IFN- $\gamma$ & $2,44 \pm 0,7^{*}$ & $2,06 \pm 0,7^{*}$ \\
\hline
\end{tabular}

Физиологически нормальные величины данных показателей были установлены в процессе динамического исследования на пятые сутки от момента начала лечения, а в группе сравнения - на десятые сутки от момента начала лечения. К этим суткам все исследуемые показатели стали соответствовать данным, полученным в группе из добровольцев без установленной патологии.

При исследовании показателей, характеризующих систему комплемента у пациентов с установленным диагнозом ХГП средней степени, после проведения комплексного и традиционного лечения установлено, что в первые сутки после начала лечения в обеих исследуемых группах было зарегистрировано статистически достоверное снижение общего количества комплемента в плазме крови, который составил $102 \pm 0,4 \mathrm{ME} /$ мл. Помимо общего количества комплемента в основной группе и группе сравнения было выявлено статистически достоверное снижение С3-фракции комплемента до $6,3 \pm 0,1$ г/л и C4-фракции комплемента, который составил 0,07 $\pm 0,3$ г/л. В динамике данные показатели изменились следующим образом: в основной группе и группе сравнения к третьим суткам существенных изменений в исследуемых показателях отмечено не было. К пятым суткам после начала лечения в группе сравнения существенной динамики выявлено не было, в основной группе было выявлено статистически достоверное увеличение всех исследуемых показателей. Так, количество общего комплемента в плазме крови составило $110 \pm$ 0,4 МЕ/мл, его С3-фракции - до 10,2 \pm 0,3 г/л и С4-фракции - до 0,10 $\pm 0,5$ г/л. Из представленных данных видно, что в основной группе происходило увеличение исследуемых показателей, однако они не достигали физиологически нормальных величин. Полное восстановление этих показателей было зарегистрировано к десятым суткам от начала лечения. В группе сравнения существенной динамики в исследуемых показателях до пятнадцатых суток отмечено не было, на пятнадцатые сутки данные показатели стали соответствовать физиологически нормальным.

В результате проведенного исследования содержания интерлекинов у пациентов с ХГП средней степени было установлено, что, также как и у пациентов с ХГП легкой степени, после первых суток от начала лечения выявлены изменения практически всех интерлекинов, за исключением IL-2 и IL-4, как в основной группе, так и в группе сравнения. 
При этом происходило статистически достоверное увеличение провоспатительных интерлекинов и снижение противовоспалительных. Происходило статистически достоверное увеличение интерлекинов, которые отнесены к провоспалительным, и снижение противовоспалительных. Полученные результаты представлены в таблице 5.

Таблица 5

Table 5

Показатели содержания интерлекинов у пациентов с ХГП средней степени и группы сравнения, полученные в первые сутки после начала лечения $(\mathrm{M} \pm \mathrm{m})$

Interlequin levels in patients with moderate chronic generalized periodontitis and comparison group obtained in the first day after starting treatment $(\mathrm{M} \pm \mathrm{m})$

\begin{tabular}{|c|c|c|}
\hline \multirow{2}{*}{$\begin{array}{c}\text { Исследуемые показатели, } \\
\text { пг/мл }\end{array}$} & \multicolumn{2}{|c|}{ Полученные результаты в группах } \\
\cline { 2 - 3 } & основная $(\mathrm{n}=20)$ & сравнения $(\mathrm{n}=20)$ \\
\hline TNF $\alpha$ & $12,21 \pm 0,7^{*}$ & $11,99 \pm 0,8^{*}$ \\
\hline IL-1 $\beta$ & $13,23 \pm 0,8^{*}$ & $12,93 \pm 0,7^{*}$ \\
\hline IL-6 & $8,23 \pm 0,7^{*}$ & $8,26 \pm 0,8^{*}$ \\
\hline IL-8 & $42,6 \pm 0,5^{*}$ & $42,9 \pm 0,7^{*}$ \\
\hline IL-2 & $0,09 \pm 0,5$ & $0,10 \pm 0,3$ \\
\hline IL-4 & $0,88 \pm 0,4$ & $0,86 \pm 0,2$ \\
\hline IL-10 & $18,5 \pm 0,6^{*}$ & $19,7 \pm 0,9^{*}$ \\
\hline IFN- $\gamma$ & $1,94 \pm 0,7^{*}$ & $1,96 \pm 0,8^{*}$ \\
\hline
\end{tabular}

На пятые сутки от момента начала лечения в основной группе регистрировалось снижение провоспалительных интерлекинов и увеличение противовоспалительных интерлекинов, однако данные показатели не достигали физиологически нормальных величин. Изменений в группе сравнения выявлено не было. Полученные результаты представлены в таблице 6.

Таблица 6

Table 6

Показатели содержания интерлекинов у пациентов с ХГП средней степени и группы сравнения, полученные на пятые сутки после начала лечения $(\mathrm{M} \pm \mathrm{m})$

Indicators of the content of interlequins in patients with moderate chronic generalized periodontitis and the comparison group, obtained on the fifth day after the start of treatment $(\mathrm{M} \pm \mathrm{m})$

\begin{tabular}{|c|c|c|}
\hline \multirow{2}{*}{$\begin{array}{c}\text { Исследуемые показатели, } \\
\text { пг/мл }\end{array}$} & \multicolumn{2}{|c|}{ Полученные результаты в группах } \\
\cline { 2 - 3 } & основная $(\mathrm{n}=20)$ & сравнения $(\mathrm{n}=20)$ \\
\hline TNF $\alpha$ & $6,17 \pm 0,4^{*}$ & $11,99 \pm 0,8^{*}$ \\
\hline IL-1 $\beta$ & $6,22 \pm 0,4^{*}$ & $12,93 \pm 0,7^{*}$ \\
\hline IL-6 & $3,16 \pm 0,8^{*}$ & $8,26 \pm 0,8^{*}$ \\
\hline IL-8 & $33,6 \pm 0,3^{*}$ & $42,9 \pm 0,7^{*}$ \\
\hline IL-2 & $0,09 \pm 0,8$ & $0,10 \pm 0,3$ \\
\hline IL-4 & $0,87 \pm 0,7$ & $0,86 \pm 0,2$ \\
\hline IL-10 & $26,5 \pm 0,4^{*}$ & $19,7 \pm 0,9^{*}$ \\
\hline IFN- $\gamma$ & $2,45 \pm 0,2^{*}$ & $1,96 \pm 0,8^{*}$ \\
\hline
\end{tabular}

Физиологически нормальные величины данных показателей были установлены в процессе динамического исследования на десятые сутки от момента начала лечения, а в группе сравнения - на пятнадцатые сутки от момента начала лечения. К этим суткам все исследуемые показатели стали соответствовать данным, полученным в группе из добровольцев без установленной патологии.

Как показывают проведенные исследования, комбинированное применение иммуномодуляторов и КВЧ-терапии позволяют значительно снизить сроки восстановления по- 
казателей, характеризующих содержание интерлекинов у пациентов с ХГП как легкой, так и средней степени тяжести.

\section{Выводы}

1. В патогенезе развития хронического генерализованного пародонтита легкой и средней степени важное значение отводится изменениям интерлекинов в сыворотке крови. При этом заболевании происходит увеличение провоспалительных и снижение противовоспалительных интерлекинов.

2. Раздельное применение КВЧ-терапии и иммуномодуляторов при лечении хронического генерализованного пародонтита легкой и средней степени не приводит к более быстрому восстановлению показателей интерлекинов в сыворотке крови.

3. Для более быстрого восстановления интерлекинов в сыворотке крови необходимо одновременное применение КВЧ-терапии и иммуномодулятора. В качестве иммуномодулятора рекомендуем использовать полиоксидоний в таблетированной форме, за 20-30 минут до приема пищи, каждый день 2 раза в сутки, семь дней. Применение данного метода позволяет нормализировать исследуемые показатели к пятым суткам при легкой степени и на десятые сутки - при средней степени хронического генерализованного пародонтита.

4. Для проведения КВЧ-терапии рекомендуем использовать аппарат, вырабатывающий КВЧ-волны «Явь-1». Время продолжительности одного сеанса, которое затрачивалось на каждого пациента, должно составлять не менее 30 мин. Общее количество процедур - 10 штук, процедуры должны проводиться один раз в день ежедневно на биологически активные точки лица.

\section{Список литературы}

1. Блашкова С.Л., Макарова Н.А. 2010. Применение полиоксидония в комплексном лечении хронического генерализованного пародонтита. Казанский медицинский журнал; 91 (5): 666-669.

2. Булкина Н.В., Китаева В.Н., Герасимова Т.В., Кропотина А.Ю., Вулах Н.А. 2018. Применение комбинированного воздействия лазерного КВЧ-облучения аппаратом «Матрикс» в комплексном лечении заболеваний пародонта. Вестник медицинского института «Реавиз»: реабилитация, врач и здоровье: $31: 49-52$.

3. Булкина Н.В., Панченко А.Д. 2011. Оценка эффективности комплексного лечения больных кандидозом полости рта с применением иммунокорригирующей терапии. Саратовский научно-медицинский журнал. Т.7-2: 477-481.

4. Иванов В.С. 2001. Заболевания пародонта. 4-е изд. М.: Мед. Информ. агентство. 300 с.

5. Истомина И.С., 2012. Крайне высокая терапия в клинической практике (часть I). Физиотерапия, бальнеология и реабилитация; 2: 47-52.

6. Казанцев А.В., Суетенков Д.Е., Фирсова И.В. 2015. КВЧ-терапия в комплексном лечении пародонтита у пациентов с зубочелюстными аномалиями: патогенетические и гендерные аспекты. Российский стоматологический журнал; 19 (4): 27-35.

7. Караков К.Г., Власова Т.Н., Оганян А.В., Каракова С.Н., Ткаченко С.С., Порфириадис М.П. 2017. Сравнительная оценка результатов лечения хронического пародонтита с применением иммуномодулятора. Главный врач Юга России, 2. 30-32.

8. Караулов А.В. 1999. Клиническая иммунология. - М.: Медицинское информационное агентство - 604 с.

9. Крайнов С.В., Михальченко В.Ф., Яковлев А.Т., Попова А.Н., Алеханова И.Ф. 2017. Глубина пародонтального кармана, или величины потери прикрепления, какой параметр выбрать в геронто-стоматологии? Проблемы стоматологии. Т. 13-4: 9-14.

10. Масляков В.В., Ерокина Н.Л., Ильюхин А.В., Низовцева С.А. 2019. Состояние иммунитета при хроническом генерализованном пародонтите. Вестник медицинского института «Реавиз»: реабилитация, врач и здоровье; 2: 105-108.

11. Морозов К.А., Матвеев А.П., Морозов Е.К., Кабанов Ю.В. 2016. Диагностика состояния опорно-удерживающего аппарата зубов. Стоматология, Т. 95, № 5, 8-11. 
12. Ошноков А.К., Брагин Е.А., Барычева Л.Ю. 2015. Цитокиновый профиль у пациентов с хроническим пародонтитом на фоне лечения с использованием VECTOR-методики. Современные проблемы науки и образования; 5. URL: http://science-education.ru/ru/article/view?id=22579 (дата обращения: 01.05.2020).

13. Попова Н.В., Гайдарова Т.А. 2010 Состояние иммунного статуса больных хроническим генерализованным пародонтитом. Acta Biomedica Scientifica; 5 (75): 146-150.

14. Прошин А.Г., Панченко А.Д., Савкина А.А., Альбекова Ю.Г., Крылова И.В. 2018. Оценка динамики изменения специфического иммуноглобулина $\mathrm{G}$ в сыворотке крови больных кандидозом полости рта со съемными пластиночными протезами в ближайшие и отдаленные сроки лечения. Вестник медицинского института «Реавиз»: реабилитация, врач и здоровье: 36: 110-114.

15. Соболева Л.А., Шульдяков А.А, Булкина Н.В., Рамазанова К.Х., Царева Т.Д. 2017. Топическая иммуномодуляция в терапии гингивита у больных с хроническими инфекционными заболеваниями. ФГБОУ ВО «Саратовский государственный медицинский университет им. В.И Разумовского» Минздрава России; 8: 281-284.

\section{References}

1. Blashkova S.L., Makarova N.A. 2010. Primenenie polioksidonija v kompleksnom lechenii hronicheskogo generalizovannogo parodontita [Use of polyoxidonium in the integrated treatment of chronic generalized periodontitis]. Kazanskij medicinskij zhurnal; 91 (5): 666-669.

2. Bulkina N.V., Kitaeva V.N., Gerasimova T.V., Kropotina A.Yu., Vulakh N.A. 2018. Application of combined effects of laser EHF irradiation with the matrix device in the complex treatment of periodontal diseases. Bulletin of the medical Institute «Reaviz»: rehabilitation, doctor and health: 31: 49-52.

3. Bulkina N.V., Panchenko A.D. 2011. Evaluation of the effectiveness of complex treatment of patients with oral candidiasis using immunocorrective therapy. Saratov journal of medical research, 7 (2): 477-481.

4. Ivanov V.S. 2001. Zabolevanija parodonta [Parodont diseases]. 4-e izd. M.: Med. Inform. agentstvo. $300 \mathrm{~s}$.

5. Istomina I.S., 2012. Krajne vysokaja terapija v klinicheskoj praktike (chast' I) [Extremely high therapy in clinical practice (Part I)]. Fizioterapija, bal'neologija i reabilitacija; 2: 47-52.

6. Kazancev A.V., Suetenkov D.E., Firsova I.V. 2015. KVCh-terapija v kompleksnom lechenii parodontita u pacientov s zubocheljustnymi anomalijami: patogeneticheskie i gendernye aspekty [EHF therapy in the integrated treatment of periodontitis in patients with dental abnormalities: pathogenetic and gender aspects]. Rossijskij stomatologicheskij zhurnal; 19 (4): 27-35.

7. Karakov K.G., Vlasova T.N., Ohanyan A.V., Karakova S.N., Tkachenko S.S., Porfiriadis M.P. 2017. Comparative evaluation of the results of treatment of chronic periodontitis with the use of an immunomodulator. Chief doctor of the South of Russia 2: 30-32.

8. Karaulov A.V. 1999. Klinicheskaja immunologija [Clinical immunology]. - M.: Medicinskoe informacionnoe agentstvo $-604 \mathrm{~s}$.

9. Krainov S.V., Mikhalchenko V.F., Yakovlev A.T., Popova A.N., Alekhanova I.F. 2017. The depth of the periodontal pocket or the amount of loss of attachment, which option to choose in gerontechnology? Problems of dentistry. 13 (4): 9-14.

10. Masljakov V.V., Erokina N.L., Il'juhin A.V., Nizovceva S.A. 2019. Sostojanie immuniteta pri hronicheskom generalizovannom parodontite [State of immunity in chronic generalized periodontitis]. Vestnik medicinskogo instituta «Reaviz»: reabilitacija, vrach i zdorov'e; 2: 105-108.

11. Morozov K.A., Matveev A.P., Morozov E.K., Kabanov Yu.V. 2016. Diagnostics of the state of the supporting and retaining apparatus of the teeth. Dentistry, 95 (5): 8-11.

12. Oshnokov A.K., Bragin E.A., Barycheva L.Ju. 2015. Citokinovyj profil' u pacientov s hronicheskim parodontitom na fone lechenija s ispol'zovaniem VECTOR-metodiki [Cytokine profile in patients with chronic periodontitis against VECTOR treatment]. Sovremennye problemy nauki i obrazovanija; 5. URL: http://science-education.ru/ru/article/view?id=22579 (data obrashhenija: 01.05.2020).

13. Popova N.V., Gajdarova T.A. 2010 Sostojanie immunnogo statusa bol'nyh hronicheskim generalizovannym parodontitom [State of immune status of patients with chronic generalized periodontitis]. Acta Biomedica Scientifica; 5 (75): 146-150.

14. Proshin A.G., Panchenko A.D., Savkina A.A., Albekova Yu.G., Krylova I.V. Evaluation of the dynamics of changes in specific immunoglobulin $\mathrm{G}$ in the blood serum of patients with oral candidia- 
sis with removable plate prostheses in the nearest and long-term treatment. Bulletin of the medical Institute «Reaviz»: rehabilitation, doctor and health: 36: 110-114.

15. Soboleva L.A., Shuldyakov A.A., Bulkina N.V., Ramazanova K.Kh., Tsareva T.D. 2017. Topical immunomodulation in the treatment of gingivitis in patients with chronic infectious diseases. Saratov state medical University named After V.I. Razumovsky, Ministry of health of Russia; 8: 281-284.

\section{Ссылка для цитирования статьи \\ Link for article citation}

Масляков В.В., Цымбал А.А., Пронина Е.А., Прошин А.Г., Ильюхин А.В. 2020. Применение комбинированной терапии КВЧ и иммуномодулятора для коррекции цитокинов при хроническом генерализованном пародонтите. Актуальные проблемы медицины, 43 (2): 274-284. DOI 10.18413/2687-0940-2020-43-2-274-284.

Maslyakov V.V., Tsymbal A.A., Pronina E.A., Proshin A.G., Ilyukhin A.V. 2020. Application of combination therapy of KVF and immunomodulator for cytokine correction in chronic generalized periodontitis. Challenges in Modern Medicine, 43 (2): 274-284 (in Russian). DOI 10.18413/2687-0940-2020-43-2-274-284. 